cases of epigenesis, such as the conformational changes of prion proteins, are of minor evolutionary significance. Still others, such as an ancestral cell's ingestion of the bacteria that evolved into mitochondria, were of immense importance in evolution but are infinitely rarer than adaptive changes based on genes. And in nearly all cases, epigenetic effects peter out after a few generations, unable to promote major evolutionary change. Perhaps the most serious criticism of epigenetics is that of the thousands of inherited mutations found in model organisms such as mice and fruit flies, virtually all reside in DNA.

The second paradigm involves "the self-righting properties of developmental systems", also known as phenotypic accommodation, which, says Blumberg, lead to evolutionary innovation. To support this, he trots out the two-legged goat described in 1942 by Dutch veterinarian E. J. Slijper. The goat, a developmental anomaly born without forelegs, learned to hop on its hindlimbs like a kangaroo. When the goat died in an accident - some say in an ill-advised experiment to see if it could walk downstairs Slijper's autopsy showed that it had undergone modifications of its spine, hindlimbs, muscles and neck that facilitated its bipedal hopping. It has been suggested that this hobbled beast is a model for the origination of bipedality in some lineages, even humans. Although Blumberg admits that this is unlikely - after all, there are perfectly good, and more parsimonious, Darwinian explanations for bipedality - he approvingly quotes anatomist Pere Alberch: "The regulatory capacities of an epigenetic system imply that any intrinsic change will trigger a sequence of regulatory changes to automatically generate an integrated phenotype." But as this integrated phenotype was not based on genetic differences from any other goat, it could not be transmitted to offspring, and its relevance to evolution is unclear. The phenotypic changes in Slijper's goat did not result from some inherent self-regulating property of development. Rather, they reflect an evolved phenomenon: natural selection has given bones and muscles the adaptive property of developing in response to the stresses they experience.

Blumberg's final alternative to conventional evolution is genetic assimilation. As with phenotypic accommodation, here the phenotype changes before the genes. During assimilation, an initial environmental change alters the phenotype of many individuals, exposing previously hidden genetic variation that can then be selected. Eventually, what was an environmental change becomes genetic, mimicking the inheritance of acquired traits.

Social learning is one way to start this process. For example, in the 1920s, two species of
British tits learned by mass imitation to pry up the foil on milk bottles and drink the cream on top. Were home milk delivery still common, one can imagine that this propensity might have become genetically assimilated. Individuals with greater abilities to learn the behaviour, or perform the actions needed, would be favoured by selection. Eventually, cream pilfering would become innate - coded in the genes. Many adaptations might have started in this way; fish, for example, may have evolved adaptations for living on land after some individuals discovered terrestrial insects to be a rich food source. But we can also explain such cases by invoking simple selection on pre-existing genetic variation. In the absence of a single credible example of genetic assimilation in nature, it remains an appealing but untested speculation.
In the end, the problem with these explanations is not so much that they are wrong, or of no potential importance in evolution. Rather, it is that Blumberg gives the impression that they are established truths rather than hypotheses that have remained unconfirmed for three decades. In his anxiety to boost the status of evo-devo in the pantheon of evolutionary subdisciplines, Blumberg has short-changed orthodoxy. Not only does the traditional view of evolution explain far more than he allows, but Blumberg shapes his own vision of development to inflate its challenge to neo-Darwinism. I, for one, am with Wolpert.

Jerry A. Coyne is a professor in the Department of Ecology and Evolution at the University of Chicago, Illinois 60637, USA.

e-mail: j-coyne@uchicago.edu

\title{
The future is now
}

"With great power comes great responsibility," uttered Stan Lee's comic-book superhero Spider-Man in his first published appearance in Amazing Fantasy in 1962. Since then, science has advanced to such a point that the human body can be enhanced in ways that mimic fiction. Cloning, face transplants, prosthetic limbs, brain-machine interfaces and cognition-enhancing drugs promise utopian or Orwellian visions of the future, depending on your outlook. It is the scientific community, not the superhero, that holds the great responsibilities of our age and the next.

Two books, Human Futures and The Science of Heroes, use a crystal ball to imagine how science will determine the future of human existence and society.

Human Futures is a varied collection of meditations on the notion of humanity from researchers, artists, philosophers and even a Blood Elf

Human Futures:
Art in an Age of Uncertainty
Edited by Andy Miah
Liverpool Univ. Press: 2008 .
368 pp. $€ 35$

The Science of Heroes: The Real-Life Possibilities Behind the Hit TV Show by Yvonne Carts-Powell Berkley Boulevard Books: 2008. 288 pp. \$15 from the present. Many of the essays focus on society's willingness, or not, to embrace new technologies. Philosopher Russell Blackford argues convincingly that a fear of new technologies is groundless and erodes liberalism. He notes that a governing state can allow new advances, such as choosing the sex of one's child, without endorsing the underlying technology or morality of an individual's choice.

The concept of human enhancement is investigated by ethicist Ruud Ter Meulen. Certain drugs such as modafinil, used to treat narcolepsy, have been shown to improve cognition and are becoming increasingly popular with students revising for exams. If everyone takes the drug in future, then what is the new norm? Will it make us better, or just different?

Physicist Richard Jones asks how humans have been enhanced by technology. He observes that the public priest from the online role-playing game World of Warcraft. The book is born of the Human Futures programme of the Foundation for Art and Creative Technology, based in Liverpool, UK. The programme comprised a series of exhibitions and lectures for public debate, in which creative assemblages of artists, philosophers and scientists explored questions of what we are now, and what we will become.

The first of the book's four sections, entitled 'Visions', perhaps best succeeds at describing the problems of the future using intelligent insights accepts the benefits of gadgets while increasingly rejecting the scientific world view. As a result, he explains, per capita energy use in the United Kingdom has risen from 20 gigajoules per person in 1800 to nine times that figure today. Life expectancy, he notes, is strongly correlated with energy use. Such a rise in energy use looks unsustainable at present, but Jones asserts that technology is a product of society, not a runaway automaton, and solutions will come as long as the energy flows.

Oddly, the section concludes with a delightful 


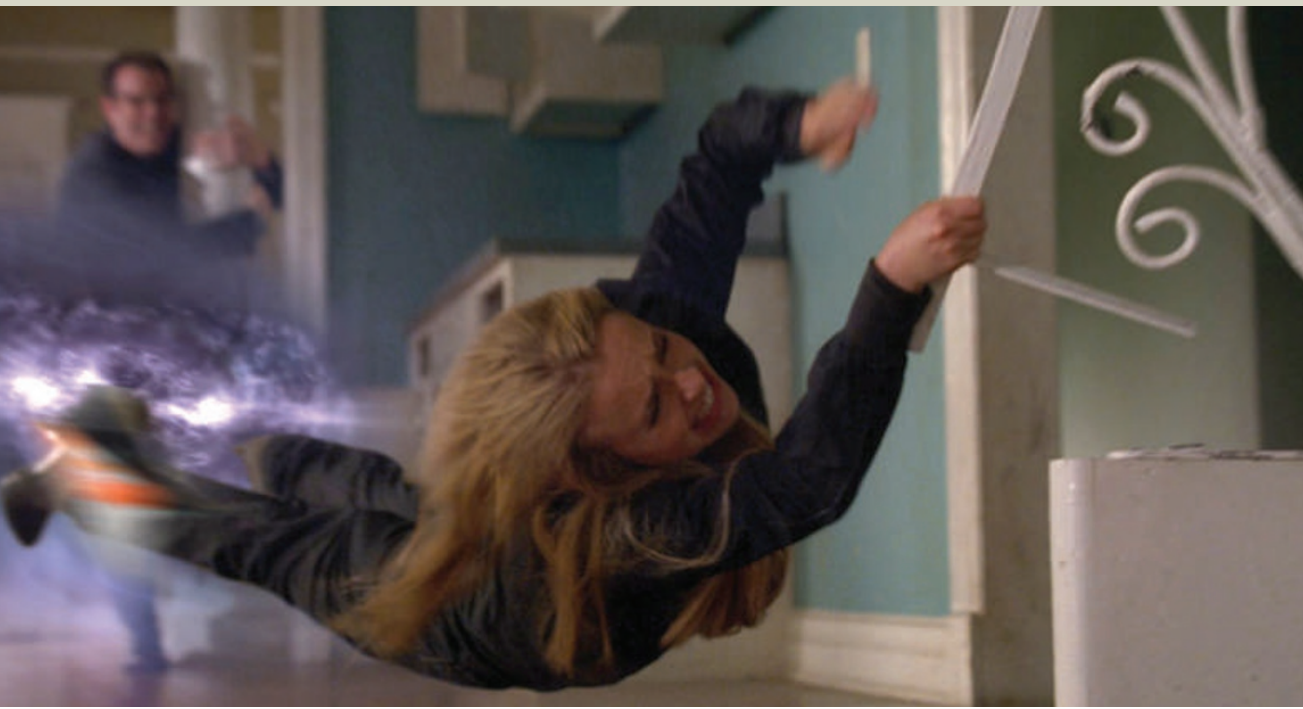

Many of the 'superpowers' portrayed in the television series Heroes are no longer science fiction.

but misplaced essay on 'evidence dolls', the creation of designers Anthony Dunne and Fiona Raby. The plastic miniatures are a hypothetical future product in which to store sperm and hair samples of prospective reproductive partners. The dolls are personified by four women, who reveal how knowledge of their partner's genes might influence their sexual and reproductive lifestyles.

Two other essays that centre on human enhancements - such as the lower-leg prostheses that allow South African runner Oscar Pistorius to compete with able-bodied athletes - are left to later sections. This misfiling of the book's content makes its arguments and themes hard to follow. Sociologist Steve Fuller's history of humans playing God is a thoughtful reminder of how badly we have handled aspects of divinity in the past, but it belongs nearer to Pramod Nayar's narrative on post-human rights. Both essays grapple with the prospect of endowing legal and moral status to our cybernetic or genetically enhanced descendants.

The book's over-designed layout - a hybrid of uber-stylish photography mixed with elements of the record sleeve from Radiohead's seminal album OK Computer - does not aid the reader experience. Indeed, the voice of musicians is absent, which weakens the book's proclamations of diversity.

The Science of Heroes explores similar themes, but in a very different style. It uses the vehicle of Heroes, the popular sci-fi television series that follows the moral chaos inflicted on a clutch of people who have incredible powers proportional to their youth and good looks. In the book, Yvonne Carts-Powell propels the reader on an enthusiastic and entertaining journey through the realms of biology and physics that might one day produce the first genuine super people.

And that day might come sooner than we think. The regenerative powers of Heroes character Claire are ones we already possess we are just slower to heal. Hiro's teleportation has been achieved, at least in the subatomic world, and metamaterials with negative refractive indexes promise invisibility for all. Other powers, such as the ability to steal memory, are already with us in the form of drugs that help victims of trauma to forget.

Historically, superheroes are a snapshot of the relationship between science and society at any one time, based on their powers and how they obtained them. From the perfect
Superman born of a 1930s United States adopting eugenic practices, to the nuclearpowered Spider-Man of the cold-war era and the psychologically disturbed Batman incarnations of the therapy-obsessed 1980s and 1990s, every generation has its super people. Those portrayed in Heroes are the genetically enhanced Generation X of the superhero world - too busy to save the world because their own lives are in perpetual turmoil.

Societies get the superheroes they need most. Human Futures and The Science of Heroes give a tantalizing glimpse of how science might make this a reality in a future human existence. And given Carts-Powell's talent for explaining the science, perhaps an army of her clones will take over high-school education.

Arran Frood is a science writer based in the United Kingdom.

e-mail: arranfrood@gmail.com

\section{Is there life on Europa?}

\author{
Unmasking Europa: \\ The Search for Life on Jupiter's Ocean Moon \\ by Richard Greenberg \\ Praxis/Springer: 2008. 278 pp \\ $€ 17.50 / \$ 27.50$
}

In the field of astrobiology, the discovery of life beyond Earth sits like a gem inside the nested Russian dolls of physics, geology, chemistry and, ultimately, biology. Efforts to understand the habitability of worlds within our Solar System began with physical and astronomical surveys, and have now moved on to the challenge of cracking open the geological secrets of key destinations such as Mars and the large, icy moons of Jupiter and Saturn.

Understanding the geological context for life is critical. Rock cycles, whether they are of silicates or ices, enable chemical cycles that can then be exploited by biological systems. Such cycles are central to life on Earth. On Mars, the demise of mantle convection may have led to the planet becoming cold and dry. Near the giant planets of the outer Solar System, and perhaps around massive extrasolar planets, rock cycles may be driven by the gravitational squeezing of icy moons due to tidal interactions. On icy moons such as Jupiter's Europa, the mixing of irradiated, oxidant-rich surface ice with a water ocean could maintain a chemically rich environment capable of sustaining life.

In Unmasking Europa, planetary scientist Richard Greenberg details in depth our geological understanding of the tidally tormented icy surface of Europa. Without pulling any punches, he also describes the equally tormented scientific debate that has led to the current canon. More than a decade after the Galileo spacecraft returned magnetic-field and gravity data that strengthened the case for a subsurface, liquid-water ocean on Europa, we still do not know whether that ocean lies beneath an ice shell just a few kilometres thick or a shell with a thickness of more than ten kilometres.

From an astrobiology perspective, a thin shell could permit direct cycling of oxidant-rich ices with the ocean. A thick ice shell, however, would impede the cycling of surface material, possibly limiting the chemical energy available to any life below the surface. On this contentious debate over the ice thickness, Greenberg notes, "by itself, modelling of heat transport on Europa is too uncertain to definitively discriminate between thin conductive or thick convective ice". However, on the basis of a host of geological features observed in images from the Voyager and Galileo missions, many of which are reproduced in the book, Greenberg argues compellingly that only a thin shell is consistent with the observed ridges, cycloidal features and chaotic terrain of Europa, all of which can be explained through tidal dynamics.

Although Greenberg occasionally strikes an acerbic tone when describing scientific differences with those on what he calls the thickice bandwagon, his motivation seems noble. He fears that "the most brilliant young minds 